versely as the radius if the density is constant, the pressure will balance the pull on a spherical absorbing particle of the density of the earth if its diameter is about a hundredthousandth of an inch. The possible effects of radiationpressure may be illustrated without going to such fineness as this. In the case of a particle of the density of the earth, and a thousandth of an inch in diameter, going round the sun at the earth's distance, there are two effects due to the sun's radiation. In the first place, the radiation-push is $x / 100$ of the gravitation-pull, and the result is equivalent to a diminution in the sun's mass. In the second place, the radiation absorbed by the particle and given out again on all sides is crushed up in front as the particle moves forward and is opened out behind. There is thus a slightly greater pressure on the advancing hemisphere than on the receding one, and this appears as a small resisting force in the direction of motion. Through this the particle tends to move in a decreasing orbit, spiralling in towards the sun. As there is good reason to believe that some comets, at least, are composed of clouds of dust, there is hope that some of their eccentricities may be explained by the existence of radiation pressure. If the particles of a dust cloud circling round the sun are of different sizes or densities, the radiation accelerations on them will differ. The larger particles will be less affected than the smaller, will travel faster round a given orbit, and will draw more slowly in towards the sun. Thus a comet of particles of mixed sizes will gradually be degraded into a diffused trail lengthening and broadening, the finer dust on the inner and the coarser on the outer edge. If a planet, while still radiating much energy on its own account, captures and attaches to itself, as a satellite, a cometary cloud of dust in which there are several different grades, with gaps in the scale of size, it may be possible that in course of time the radiation-pressure effects will form the different grades into different rings surrounding the planet. Such may possibly be the origin of the rings of Saturn.

\section{GEOGRAPHICAL RESULTS OF THE TIBET MISSION.}

THE paper read by Sir Frank Younghusband at the Royal Geographical Society on Monday, February 13, was one of the most interesting and instructive that the fellows of that society have been privileged to listen to for many years. It afforded a striking exemplification of the advantages of a due coordination of geographical facts and their combination, by a master-hand, into a well-arranged whole. The country traversed by the Tibet mission was by no means a terra incognita to the geographer, for its main features had long been known through the labours of the zealous native explorers of the Survey of India. But it is none the less true that Sir Frank Younghusband's admirable descriptions of the conditions of nature and man in that romantic region enabled his audience to realise those conditions in a way that was never before possible, and brushed away many false ideas which had been previously entertained. The speaker was also able to touch briefly upon some of the results obtained by the scientific experts who accompanied the mission, as well as by the survey party under Captains Rawling and Ryder, which in the late autumn did excellent work along the whole course of the Upper Brahmaputra, proving definitely that no peaks higher than Everest exist on this flank of the Himalayas.

In regard to the general nature of the country traversed, Sir F. Younghusband was able to correct the current idea that the whole of Tibet is more or less barren and worthless. This may be true for northern Tibet, the part traversed by recent European explorers, but not for the southern third, which is dotted over with thriving villages and well-built residences. The valleys in which Lhasa, Gyantse, and Shigatse are situated, as well as that of the Brahmaputra, are neither barren plateaux nor narrow, V-shaped gorges, but flat valleys covered with good soil, well irrigated, and richly cultivated. The passage to Tibet, as made by the Kongra-lama Pass, involves, however, a sudden change from the deep-cut valleys and luxuriant vegetation of Sikkim to wide plains on which not a tree is to be seen, while if, in some secluded nook, a plant a foot high is met NO. I 842 , VOL. 7 I] with it is a curiosity. The summer climate of Khambajong was described as charming, while the unrivalled panorama of the Himalayas, at the very culminating point of their grandeur, is a full compensation for anything that may be otherwise lacking. Sir Frank Younghusband's eloquent descriptions of the snowy range as seen from the north, with the ever-varying atmospheric effects, are of special interest as the first ever given by a European capable of appreciating adequately the glories of the prospect.

The discovery by Mr. Hayden, of the Indian Geological Survey, of a bed of fossil oysters, permitted an accurate determination of the age of the hills in this part of Tibet, showing them to be geologically quite recent, though somewhat older than the main axis of the Himalayan range. The Chumbi Valley, through which the final advance was made, is less wide and open than the valleys in Tibet proper, of which, in fact, it is not considered a part. The passage hence into Tibet, made during the height of winter by the Tang-la Pass, 15,200 feet high, involved much suffering from the effects of the great cold ( $\mathrm{r} 8^{\circ}$ below zero Fahr.) combined with the rarity of the air. The subsequent march over the elevated plateau was made in the teeth of bitter winds and blinding blizzards, which continued through January, February, and March. But on arrival at Gyantse (April II) the pirring cold was left behind. Willow and poplar trees were bursting into foliage, and the banks of the river were covered with masses of iris-plants, which later on became sheets of purple. On July 14, the day of the start for Lhasa, heavy rain destroyed the delusion that Tibet is a rainless country. Frequent rain was experienced until September, and the size of the rivers showed that this part of Tibet receives - probably up the Brahmaputra Valley-a quite considerable rainfall. Finally, in a lovely vallev covered with trees, rich with cultivation, and watered by a river as broad as the Thames at Westminster, the mysterious city which no living European had seen before was at last reached, hidden away by range after range of snowy mountains. It proved anything but a dreamland city, and its streets were horribly muddy, but the grand lama's palace was an imposing, massive structure. Even the leading men were of low mental calibre, having much of the nature of children. The $\mathrm{Ti}$ Rimpochi-the leading lama-though benevolent and genial, had few intellectual attainments, and was firmly convinced that the earth was triangular; while the religion of the Tibetans was described as the most degraded form of Buddhism in existence.

\section{THE LONDON CONFERENCE ON SCHOOL HYGIENE.}

THE conference on school hygiene, organised by the Royal Sanitary Institute, met on February 8,9 , and 1o at the University of London. Sir Arthur Rücker, who was installed as president of the conference, delivered an address in which he insisted that the elements of education should include some knowledge of the dangers by which mankind is surrounded and of the means to keep them at bay, and that those to whom young lives are entrusted should learn the main outlines of hygiene.

The ignorance of household management and of the principles of hygiene among the poor is responsible in no small measure for their high preventable mortality, their inferior physique, their intemperance and their poverty. How possible it is to better the conditions of modern life, and thus to improve the health, happiness, and physical powers of the people, and thereby their mental vigour and industrial efficiency, is generally recognised, and to this end a suitable hygienic education, moral and material, of the future parents seems essential. Not only have 15,000 medical men and the Commissions on Physical Degeneration recommended that such teaching should be made compulsory, but the English Board of Education and the Scotch Education Department have accepted that recommendation. It is important that from the earliest years of school life children should be taught by example as well as precept the elements of healthy living. The knowledge that may be procured subsequent to that age is often gained at the price of a needlessly costly personal experience. The object, then, of school hygiene is to secure for 